\title{
In situ experimental techniques to study the mechanical behavior of materials using X-ray synchrotron tomography
}

\author{
Sudhanshu S Singh ${ }^{1}$, Jason J Williams ${ }^{1}$, Peter Hruby ${ }^{1}$, Xianghui Xiao ${ }^{2}$, Francesco De Carlo ${ }^{2}$ and Nikhilesh Chawla ${ }^{1 *}$
}

\author{
* Correspondence: \\ nchawla@asu.edu \\ ${ }^{1}$ Materials Science and Engineering, \\ Arizona State University, Tempe, AZ \\ 85287-6106, USA \\ Full list of author information is \\ available at the end of the article
}

\begin{abstract}
In situ X-ray synchrotron tomography is an excellent technique for understanding deformation behavior of materials in 4D (the fourth dimension here is time). However, performing in situ experiments in synchrotron is challenging, particularly in regard to the design of the mechanical testing stage. Here, we report on several in situ testing methods developed by our group in collaboration with Advanced Photon source at Argonne National Laboratory used to study the mechanical behavior of materials. The issues associated with alignment during mechanical testing along with the improvements made to the in situ mechanical testing devices, over time, are described. In situ experiments involving corrosion-fatigue and stress corrosion cracking in various environments are presented and discussed. These include fatigue loading of metal matrix composites (MMCs), corrosion-fatigue, and stress corrosion cracking of Al 7075 alloys.
\end{abstract}

Keywords: X-ray tomography; In situ; Fatigue; Corrosion; Crack; AA7075

\section{Background}

A sound understanding of mechanical behavior requires a thorough understanding of the evolution of deformation with time. Traditionally, the study of material structure has been limited by two dimensional (2D) analyses. This approach is often inaccurate or inadequate for solving many cutting-edge problems. In addition, it is often laborious and time-consuming. We can now use three dimensional (3D) tools and analyses to resolve time-dependent (4D) evolution of a variety of important phenomena [1-4].

$\mathrm{X}$-ray tomography is an extremely promising, non-destructive technique for characterizing microstructures in 3D and 4D. The use of high brilliance and partially coherent synchrotron light allows one to image multi-component materials from the sub-micrometer to nanometer range.

Over the years, many ex situ X-ray tomography experiments have been performed to study the behavior of materials under mechanical loading [5-7]. These experiments have consisted of post-mortem characterization after testing. More recently, in situ mechanical testing has become more attractive, as a means of visualizing and quantifying microstructural changes as a function of time. Experiments under tension [8-10], cyclic loading [11-14], corrosion-fatigue [15], and creep [16,17] have been conducted.

Several challenges exist when designing an in situ mechanical testing stage for synchrotron tomography beamlines. The stage will be on top of several motion stages which have 
weight limits for precise and reproducible movement. This constrains the size and weight of the motorized linear actuator. Also, since precise rotational movement is necessary for tomography, so the load frame's weight must be distributed as symmetrically as possible about the rotational axis. In addition, the stage requires an X-ray transparent material in the scanning area which should also be able to bear the applied load without excessive deformation. Furthermore, the load train has to be precisely aligned for the smaller samples used in tomography. This becomes even more important for in situ experiments on fatigue crack growth, for example. Finally, the distance between the fixture and the detector should be sufficient enough such that there is no contact between the load bearing sleeve and the scintillator during scanning. This can potentially affect the amount of absorption (density-based) contrast, with smaller distances yielding more absorption contrast.

In this paper, we report on several in situ testing methods developed in our group at ASU in collaboration with scientists at the Advanced Photon Source at the Argonne National Laboratory. We begin by describing our initial attempts at in situ loading in tension. This is followed by a discussion of the important issues associated with alignment, both in tension and in fatigue loading. Finally, we conclude with a section on in situ experiments in corrosion and moisture environments, which carry with them a unique set of challenges.

\section{Experimental details on X-ray synchrotron tomography}

$\mathrm{X}$-ray tomography was performed at the 2-BM beamline of the Advanced Photon Source (APS) at Argonne National Laboratory. The details of the tomography system at 2-BM have been described elsewhere [18-20]. In all the experiments, a monochromatic beam with energy of $\sim 24 \mathrm{keV}$ (except in the case of corrosion-fatigue experiment, where pink beam was used and will be described later) was focused on the specimen. A scintillator screen $\left(\mathrm{CdWO}_{4}\right.$ or LuAG:Ce) was used to convert the transmitted X-rays to visible light. This was coupled with an objective lens and a camera (CoolSnap K4 CCD or PCO Dimax CMOS camera) to obtain images. 2D projections were acquired at angular increments of $0.12^{\circ}$ over a range of $180^{\circ}$. The tomography at one time step can be completed in about 15-20 minutes when a monochromatic beam is used. These 2D projections were then input into a filtered back-projection reconstruction algorithm (Shepp-Logan filter) to obtain 3D information.

\section{Tensile and fatigue behavior}

Our initial in situ loading stage used to perform tensile tests is shown in Figure 1. The stage was designed to be less than $2 \mathrm{~kg}$ due to the weight limit of the motion stages at the 2-BM beamline. The vertical range where the region of interest on the sample must intersect the X-ray beam is often restrictive and was between $15 \mathrm{~mm}$ to $40 \mathrm{~mm}$. Thus, the distance from the bottom of our fixtures to the center of the sample was chosen to be $30 \mathrm{~mm}$ - a distance that included the base plate, sub-miniature load cell, bottom sample clamp and half the sample. In the loading stage, the specimen was clamped between the actuator and the load cell. The load cell at the bottom of the loading stage was attached to a fixed lower grip. The upper grip was attached to the stepper motor with linear actuator, which imposes a displacement on the sample to achieve the desire load. A stepper motor was chosen because it could be easily integrated with motor 


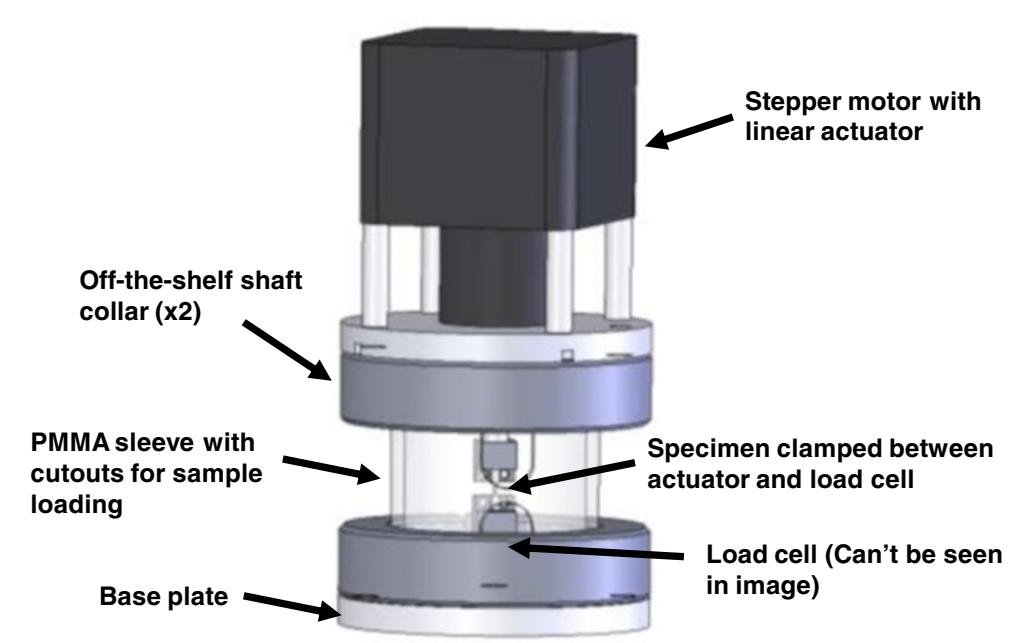

Figure 1 Initial in situ mechanical testing stage with no provision for alignment.

drives already present at the beamline. The stepper motor had a captive linear actuator capable of $8 \mu \mathrm{m}$ per step and a total stroke of $12 \mathrm{~mm}$. The load cell had a capacity of $500 \mathrm{~N}$.

The load was transmitted from the top of the stage to the bottom through a polymer sleeve (Poly methyl methacrylate or PMMA). The PMMA material was chosen due to its transparency to X-rays. Two holes were incorporated in the PMMA sleeve to facilitate the loading of the sample. A simple linear elastic finite element analysis (Cosmos Xpress, Solidworks 2008, Concord, MA) was conducted to determine the stresses and displacements in the sleeve, as shown in Figure 2(a). The modulus of the PMMA was taken as 2.4 GPa and the Poisson's ratio as 0.35. The displacement of the bottom face was constrained and a compressive load of $200 \mathrm{~N}$ was applied to the top face. The calculated stress in the region between the holes was only about $0.1 \mathrm{MPa}$. The displacement in the sleeve was also quite small, on the order of a few micrometers. In addition, experiments at the load of $200 \mathrm{~N}$ were conducted to determine the creep rate of the sleeve, if any, during the tomography operation of about 20 minutes (Figure 2b). A negligible displacement rate of $2.5 \mathrm{~nm} / \mathrm{min}$ was obtained, showing that the displacement in the PMMA did not affect the results significantly.

It is well known that axial alignment is critical during mechanical testing. This is particularly important due to the somewhat smaller sizes of specimens used in in situ X-ray tomography, because the bending moments can be exacerbated. Grips can have both concentric and angular (axial) misalignments. Concentric misalignment shifts the vertical axes of the grips laterally away from each other whereas angular misalignment occurs when upper grip's loading axis is at an angle with the lower grip's loading axis. Figure 3 shows a design that incorporates specimen alignment capability. It was designed such that concentric clamp misalignment could be minimized by translating the top clamp in two orthogonal directions with respect to the bottom clamp using the four set screws. Axial misalignment could be minimized by tilting the top clamp about two orthogonal axes with respect to the bottom clamp using the four tilt screws. The top clamp was also allowed to freely rotate about its mounting screw to self-align in the third rotational direction. In addition, a bushing was provided to reduce the lateral deflection of the actuator. 
a
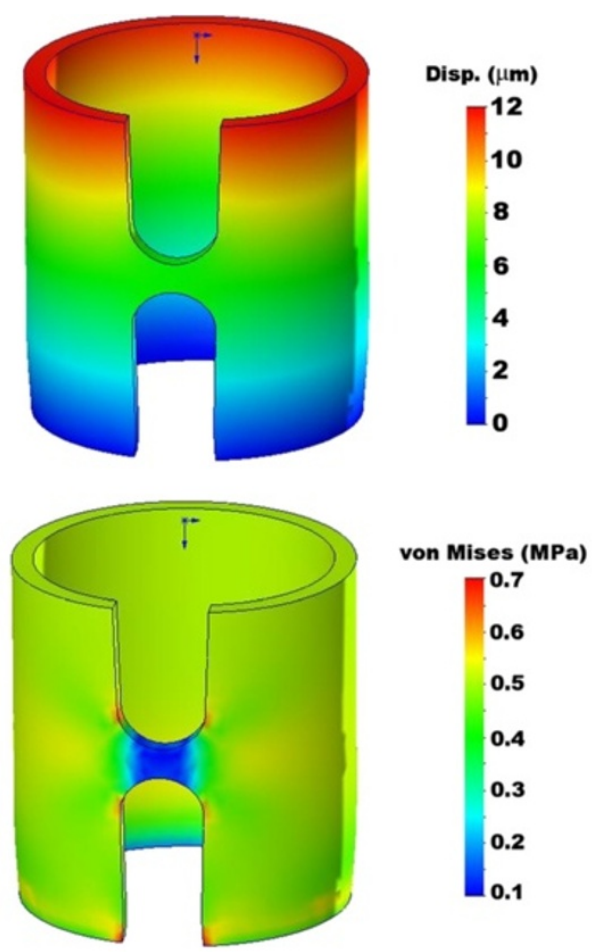

b

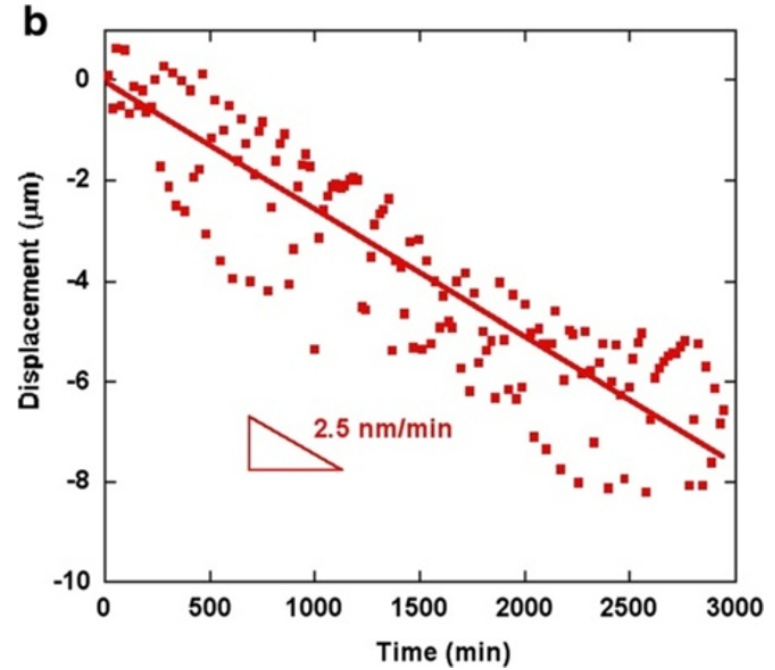

Figure 2 Finite element modeling of in situ mechanical testing system. (a) Modeling of displacement and stress in PMMA sleeve. (b) Experimental measurements of displacement in sleeve, at maximum load, for time required for tomography. Both stresses and measured displacements are negligible.

The amount of stress in the specimen prior to the self-alignment was small and therefore it did not affect the crack growth behavior.

A straight and parallel alignment specimen was used for initial alignment. It was machined such that it would only fit in the upper and lower grips if they were closely aligned. The benefit of X-ray tomography is the fact that 3D data sets are available, so we used actual images from X-ray tomography for finer alignment, without having to resort to strain gauges. By applying increasing loads to the pre-cracked specimen and measuring crack opening displacements, concentric alignments could be made to 


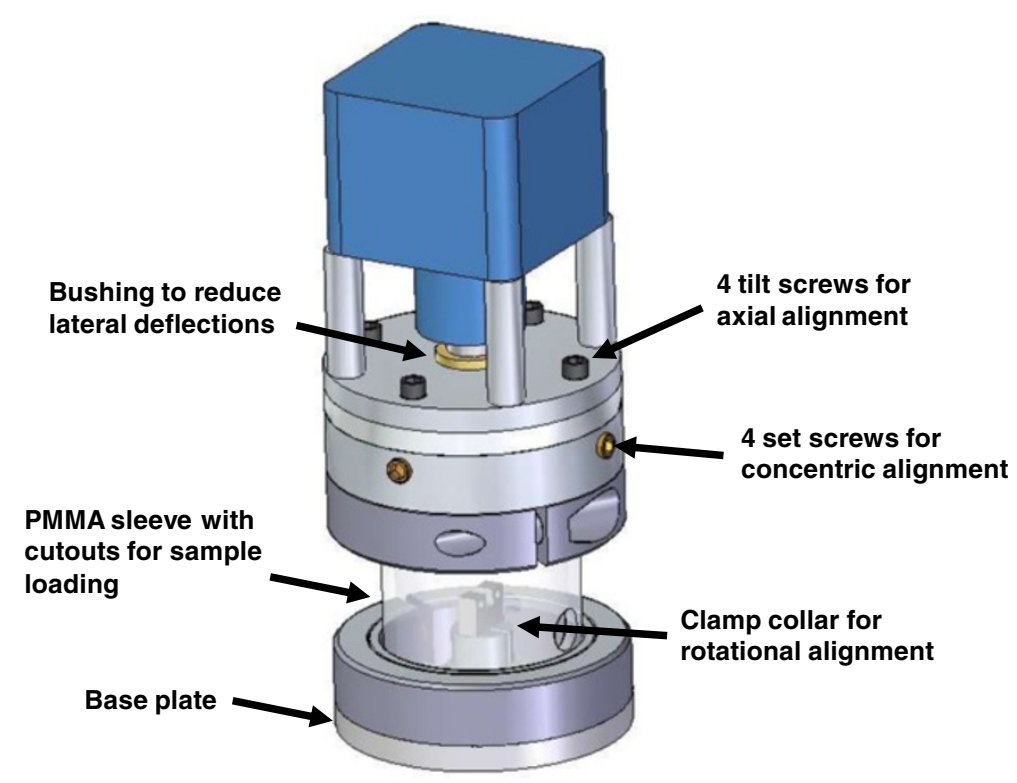

Figure 3 In situ mechanical testing stage with precision alignment fixture.

reduce the contributions from cracking in modes II and III. After alignment, the $\mathrm{x}$-axis misalignment was about $1.8 \mu \mathrm{m}$, close to zero in the $\mathrm{y}$-axis, and the tilt misalignment about $0.21^{\circ}$, as shown in Figure 4. A symmetric crack growth front was observed when alignment was performed compared to misaligned condition, as shown in Figure 5. It can be seen that with misalignment, the crack grows much further on the right side of the specimen whereas the crack is quite symmetric after alignment.

A few limitations of the loading stage include the maximum cyclic frequency of $2 \mathrm{~Hz}$ and the maximum load of only $500 \mathrm{~N}$. Also, given that the fixture must rotate 180 degrees, and that it has a load bearing sleeve, $50 \mathrm{~mm}$ was the closest distance our samples could safely be from the scintillator without hitting it - a distance that yields significant phase contrast when using $24 \mathrm{keV} \mathrm{X}$-rays (produced by a bending magnet).

Using the second loading stage shown in Figure 3, in situ fatigue crack growth tomography was performed on AA7075-T651 samples [12,13]. The fatigue crack growth rates obtained from these experiments $[12,15]$ were comparable to published data by others [21]. The errors in the $\Delta \mathrm{K}$ (stress intensity factor range) measurements were up to a maximum of only $7 \%$ due to error in measurement of force. The crack lengths can be measured accurately with an error of 1-2 pixels, the effect of which was very small in the crack growth rates $(\mathrm{da} / \mathrm{dN})$ and $\Delta \mathrm{K}$ measurements. To achieve higher resolutions in tomographic reconstructions, the width of our samples was chosen to be about $2.8 \mathrm{~mm}$ to achieve a desired resolution of $2 \mu \mathrm{m}$. A single edge-notched (SEN) geometry was chosen for these experiments because a CT specimen would be too wide to fit into a $3 \mathrm{~mm}$ field of view (necessary to achieve a $2 \mu \mathrm{m}$ resolution), and a $3 \mathrm{~mm}$ wide MT specimen could not be machined precise enough to achieve symmetric crack nucleation on each side of the central hole. The experiments were performed in the Paris law regime because of the limited amount of time available at the beamline (typically three days), and because the highest cycling frequency achieved by our linear actuator was only $2 \mathrm{~Hz}$. 

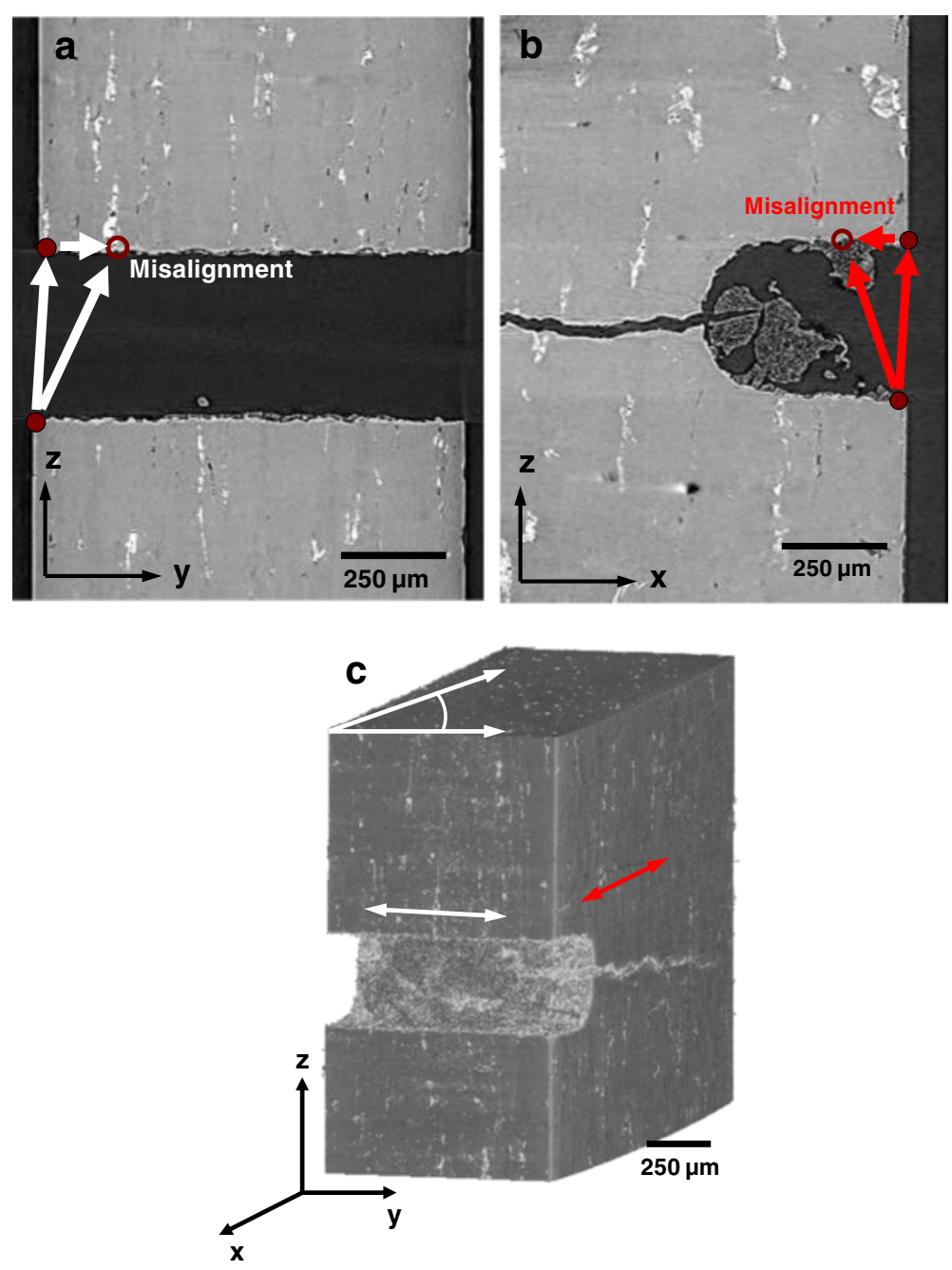

Figure 4 Two dimensional (2D) X-ray tomography slices showing types of misalignment (a) crack growing into the plane, (b) side surface of the specimen and (c) 3D rendering showing axial and angular misalignment.

The third generation in situ mechanical testing stage also incorporated load-control capability. Previously, the amount of displacement was manually monitored and was adjusted throughout the crack growth tests to maintain a pseudo-constant load amplitude, $\Delta \mathrm{P}$. The design of the third stage (Figure 6) included the ability to automatically control the actuator using feedback from the load cell. Additionally, the sample was inserted from the top of the stage rather than from the cut outs in the sleeve. The reason for this was that small cracks were observed over time near cut outs due to the combination of the applied load and the use of pink beam (used in corrosion-fatigue). Thus, a wider, shorter sleeve was used to facilitate sample loading and to increase load frame stiffness to perform fatigue tests at high R-ratios. The actuator's stroke length was also increased to $25 \mathrm{~mm}$ to provide more clearance during sample loading.

We present some preliminary results on the fatigue tests at high $R$-ratio $(R=0.6)$ in Al-SiC metal matrix composites (MMCs) using the third loading stage. The effect of high R-ratio on the crack propagation in MMCs has not been well understood. A 2080 aluminum alloy $(3.6 \% \mathrm{Cu}, 1.9 \% \mathrm{Mg}, 0.25 \% \mathrm{Zr}$ ) reinforced with 20 volume percent $\mathrm{SiC}$ 


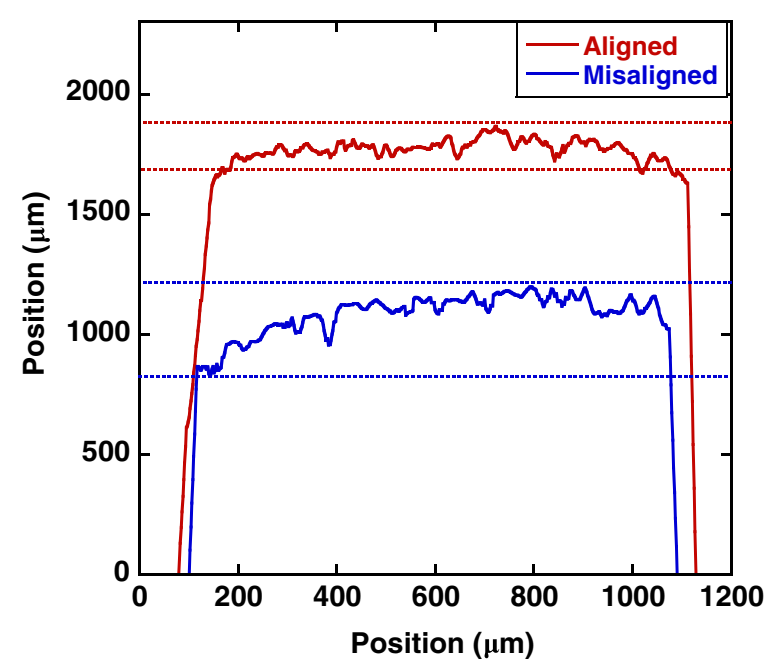

Figure 5 Comparison of crack profile (through thickness) before and after alignment. Note that the crack front is relatively symmetrical after alignment.

particles (average particle size of $25 \mu \mathrm{m}$ ) was used. The composite was processed by blending $\mathrm{SiC}$ and $\mathrm{Al}$ powders, compacting the powder mixture, hot pressing, and hot extrusion (Alcoa Inc., Alcoa, PA). Details of the powder metallurgy process for fabrication of these composite materials can be found elsewhere [22]. SEN specimens were machined by EDM for the fatigue tests.

2D X-ray synchrotron tomography images showing the progression of fatigue cracking have been shown in Figure 7. The fracture of a particle ahead of the crack tip during high load ratio fatigue can be clearly seen. Figure 7a shows that the particle (circled) was not fractured when the experiment was paused for tomography after 7,000 fatigue cycles. However the particle fractured at 8000 cycles (Figure $7 \mathrm{~b}$ ) and then the crack passed through the same fractured particle as shown in Figure 7c. This provides insight into the fundamental understanding on how the fatigue crack interacts with $\mathrm{SiC}$ particles, and the

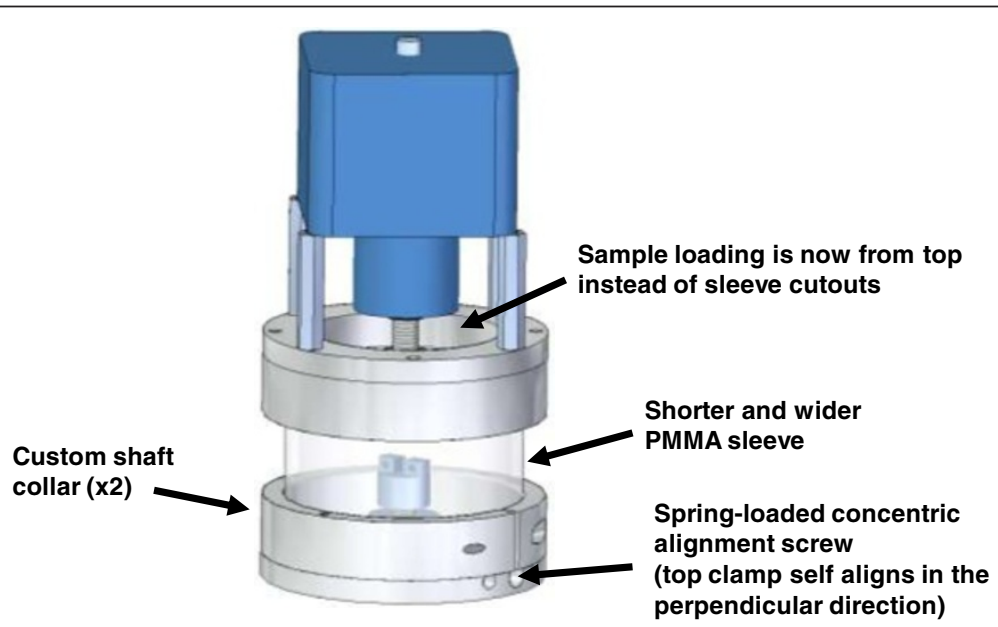

Figure 6 Third generation in situ loading stage to perform mechanical testing with load-control capability and additional stiffness for higher R-ratio fatigue crack growth experiments. 

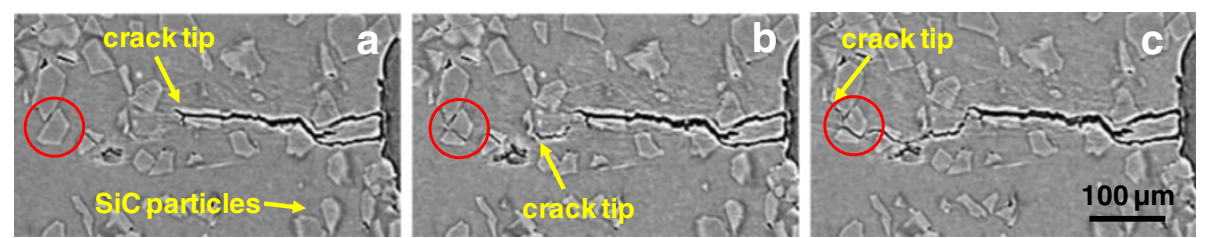

Figure $7 \mathrm{SiC}$ particle (circled) at (a) 7000 cycles, just before it fractured, (b) 8000 cycles, just after it fractured, and (c) 21000 cycles, just after main fatigue crack passes through the particle.

role of particle fracture, both ahead and right at the crack tip, in controlling fatigue crack propagation at high R-ratios.

\section{Corrosion-fatigue and stress corrosion cracking (SCC)}

In order to study the effects of corrosion-fatigue as well as stress corrosion cracking, new designs were developed. Corrosion-fatigue experiments were performed in a liquid environment, as shown in Figure 8. The PMMA sleeve has not been shown here in order to clearly show the arrangements inside the stage. Corrosion-fatigue experiments were performed on AA7075-T651 in EXCO solution (4 M NaCl, $0.5 \mathrm{M} \mathrm{KNO}_{3}$ and $0.1 \mathrm{M} \mathrm{HNO}_{3}$ ). EXCO was chosen to ensure a significant amount of corrosion in the

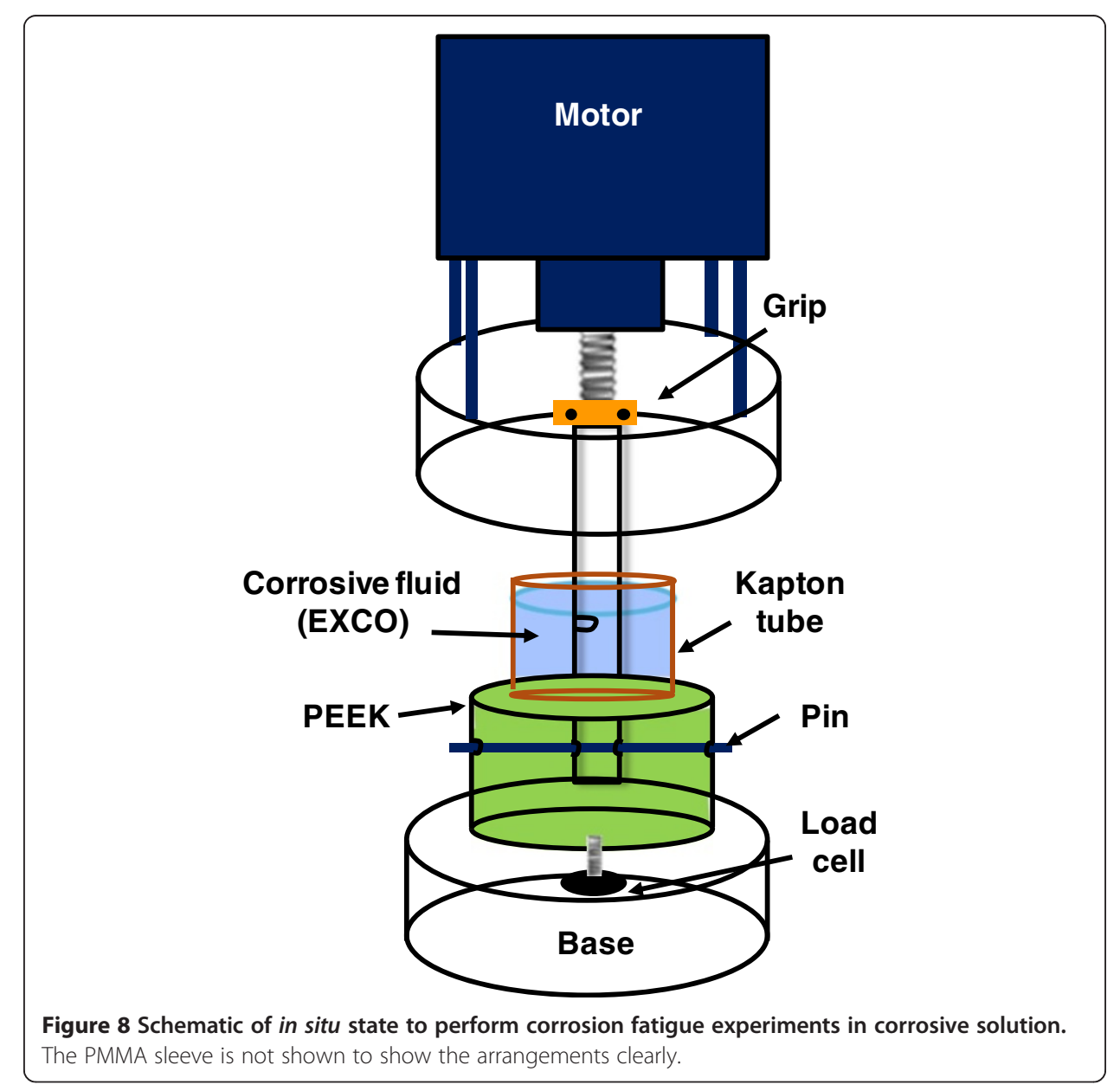


limited time available at the synchrotron beamline. SEN specimens were machined along LT orientation by EDM for the corrosion-fatigue tests. The biggest challenge in the experiment was to avoid the reaction of corrosive fluid with any part of the loading stage, especially the grips. Therefore, the material used for the bottom grip must be chemically inert to the solution while also sustaining the applied load. A polymeric PEEK (Polyether ether ketone) cylindrical grip was chosen to replace the bottom steel grip since it is chemically resistant to the solution and has good mechanical strength [23]. The bottom grip was fitted with the load cell. A rectangular hole was made at the top part of the PEEK grip to accommodate the sample. A hole was made on the side wall of the cylindrical grip to accommodate the stainless steel pin which passes through the hole made in the sample. Epoxy was added to make this a permanent and strong connection. The top part of the sample was clamped as previously described. Kapton tubing, which is also chemically inert to EXCO solution, was attached to the PEEK cylinder with wax to hold the solution around the sample during the test. The height of the Kapton tube was chosen such that the notch of the specimen was immersed in the corrosive fluid.

"Pink beam", which is a polychromatic beam with low and high energies removed from the white beam spectrum, was used during corrosion experiments, because the higher photon flux compared to a monochromatic beam allowed for significantly faster data acquisition. Thus the progression of corrosion could be documented with a higher frequency. While a typical scan with a double-multi-layer monochromatic (DMM) beam takes twenty minutes to complete, a pink beam scan can take only $0.5-1$ second. Although much faster scans are technically possible using a pink beam, significant X-ray attenuation by the corrosive fluid required higher exposure times ( $2-3$ minutes) to achieve a suitable signal-to-noise ratio.

Using the above design, we showed that the fatigue crack growth rate of AA7075-T651 was much higher in EXCO solution than in ambient air [15]. Figure 9 (a) shows a 2D X-ray tomography image of the fatigue crack along with corrosion product and the hydrogen bubbles inside the crack formed due to reaction between AA7075 and the EXCO solution. As shown in Figure 9(b), the 3D reconstruction of the crack, bubbles, corrosive fluid and corrosion products was performed using commercially available software (MIMICS, Ann Arbor, MI). Corrosion products were segmented on a few slices (from the part of crack), as shown in Figure 9(b). Figure 10 shows the changes in the shape of the bubbles and the formation of a new bubble in a fatigue cycle. Formation of a new hydrogen bubble can be clearly seen at position 3 which was not present in position 2. All bubbles were squeezed as the crack closes during unloading (position 4). These results provided insights to the fundamentals of evolution of hydrogen bubbles inside a growing fatigue crack. In particular, local variations in $\mathrm{pH}$ cause inhomogeneous formation of reaction products and will affect crack growth.

The presence of moisture in the environment is known to deteriorate the mechanical properties of high strength alloys. In order to understand the effect of moisture, in situ stress corrosion cracking (SCC) experiments were conducted in moisture, as shown in Figure 11(a). The PMMA sleeve has not been shown here for clear visualization of the arrangements inside the stage. The sample was loaded on both sides using steel grips attached to the actuator on one side and the load cell on other. To introduce moisture 


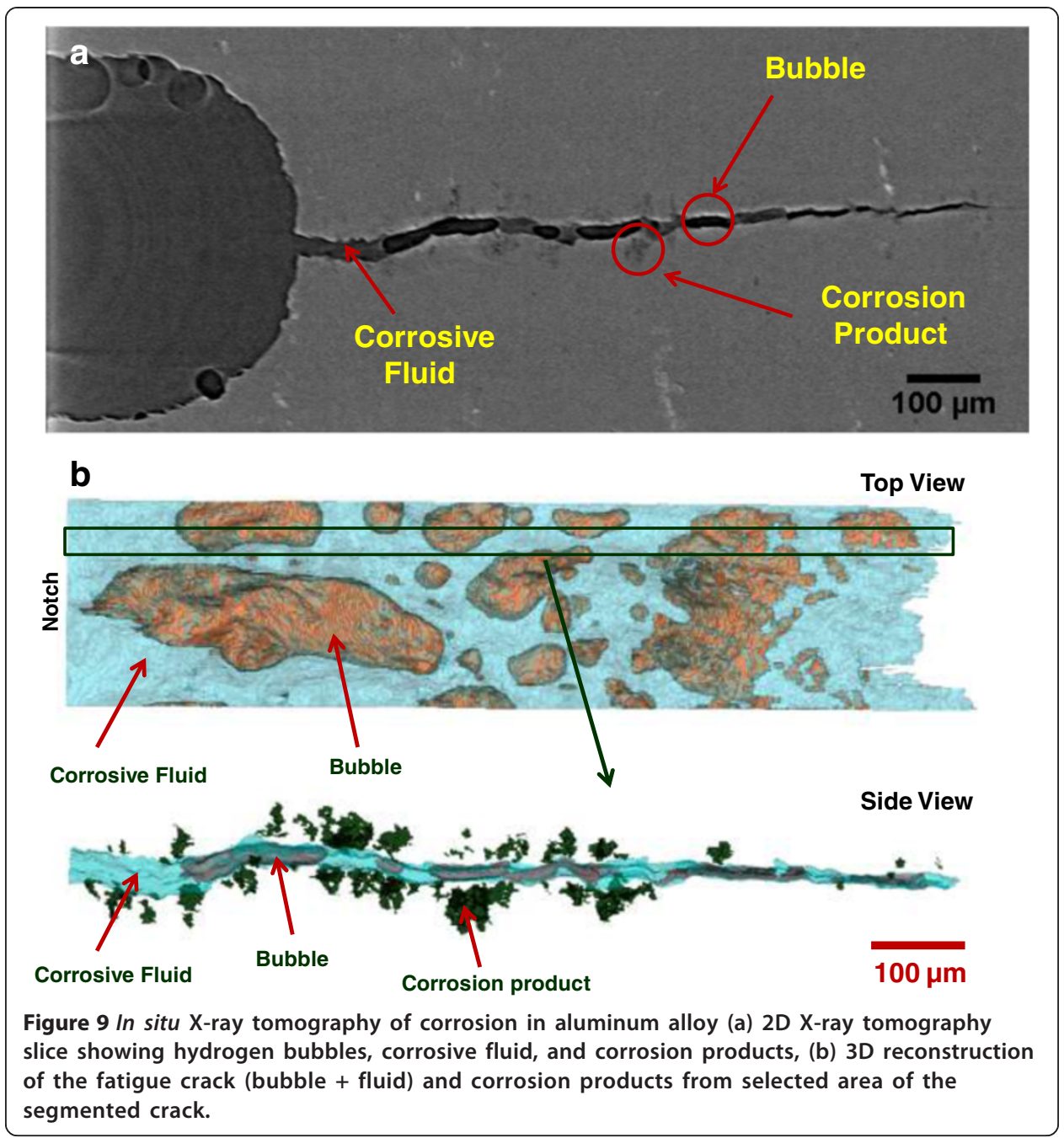

in the cell, an annular (ring shape) wet sponge was placed around the load cell at the base of the loading stage (a gap was provided between load cell and the sponge). Since stress corrosion cracking experiments require long time exposure of moisture, maintaining the constant humidity inside the chamber is a big challenge and is also critical to minimize the variability in results. In order to minimize the loss of moisture and to maintain constant relative humidity, the top part of the loading stage was covered with a plastic wrap as shown in Figure 11a. A humidity sensor was placed in front of the notch to measure the relative humidity throughout the test. These arrangements led to the constant humidity of $95-96 \%$ inside the system throughout the test, as shown in Figure 11b.

The in situ stress corrosion cracking experiment was performed on AA7075 in under-aged (UA) condition under constant load. The under-aged AA7075 was used due to the limited time available at the synchrotron beamline as it has already been established that the under-aged alloy is most susceptible to stress corrosion cracking in moisture [24]. Small SEN specimens were machined along the ST orientation by EDM for the SCC tests. Preliminary results obtained from these arrangements are shown in Figure 12, which contains 2-D X-ray tomography images of a SCC crack over time at 

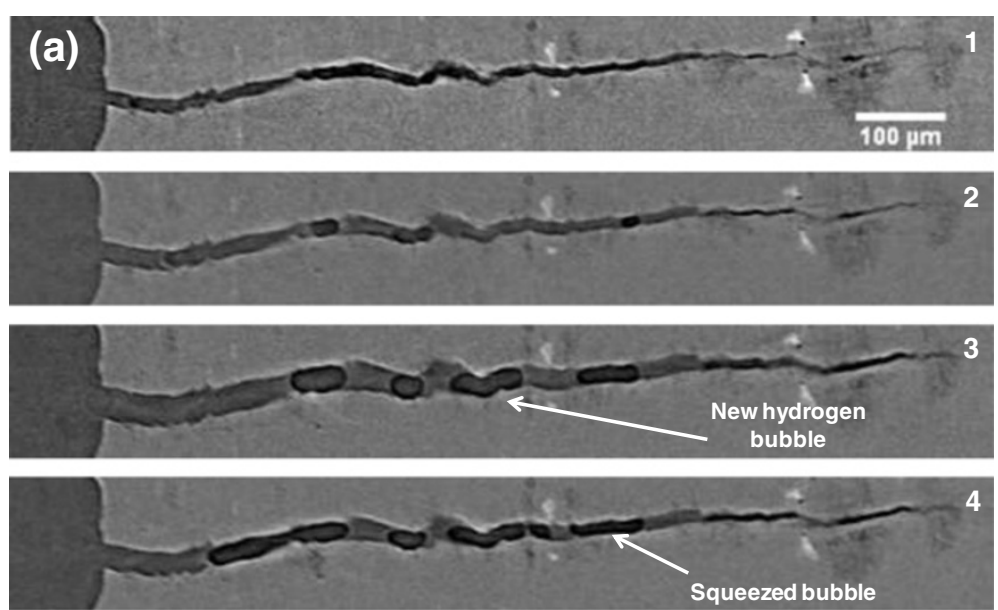

(b)

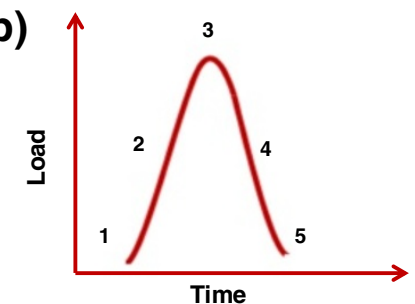

Figure 10 Loading-unloading sequence during in situ corrosion-fatigue. (a) 2D X-ray tomography images showing the formation of hydrogen bubble and the changes in morphology of bubbles in a fatigue cycle (b) corresponding fatigue cycle.

(a)
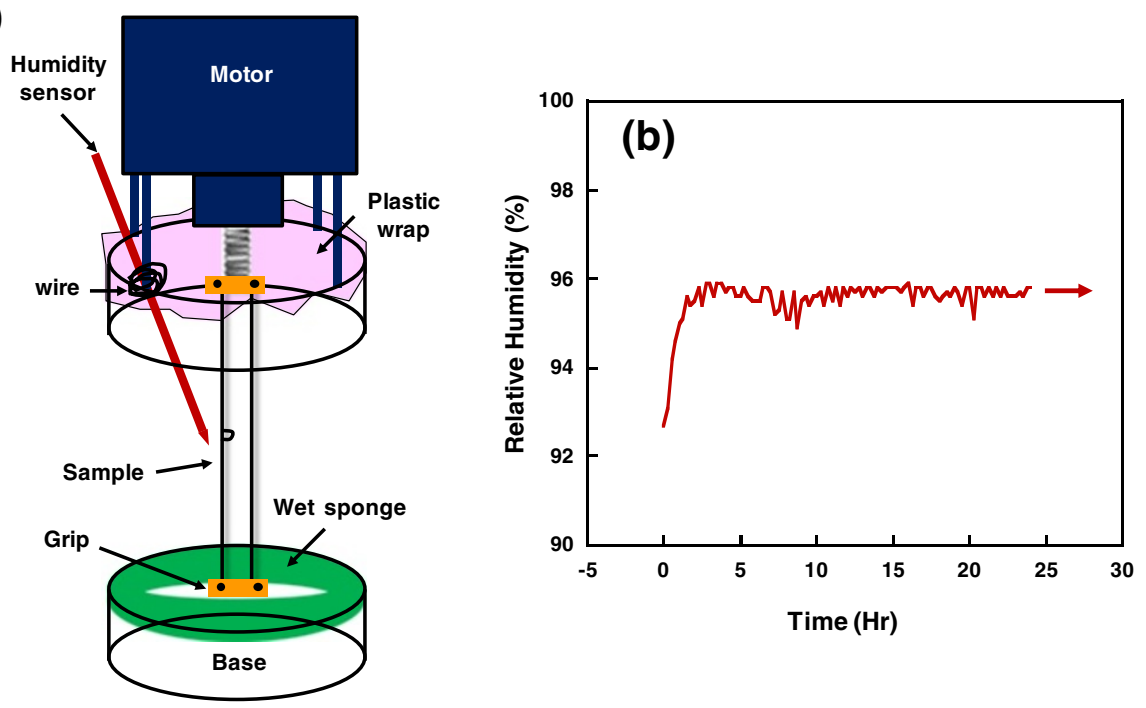

Figure 11 3D in situ stress corrosion cracking experiments in moisture. (a) Schematic of in situ stage for experiments in moisture. The PMMA sleeve is not shown to show the arrangements clearly and

(b) relative humidity as a function of time. The relative humidity remains constant throughout the test. 

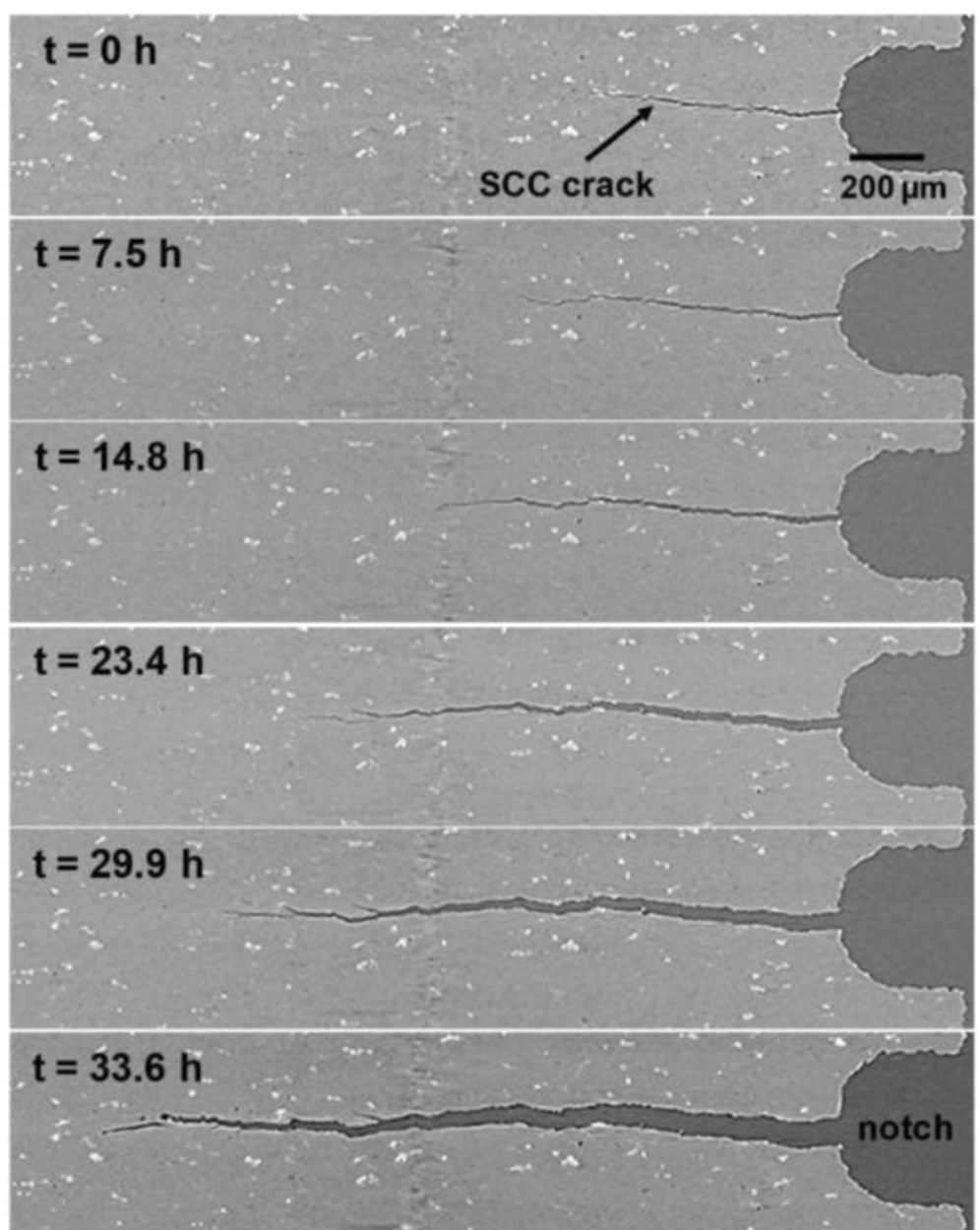

Figure $12 \mathrm{X}$-ray synchrotron tomography images of the center of the specimen with time. The crack is growing at constant load (SCC).

constant load at the center of the specimen. These results show that the SCC tests in moisture can be performed by these arrangements. It should be noted that the same arrangements can be used to perform fatigue test in moisture by changing the constant load to cyclic load.

\section{Summary}

In situ techniques using X-ray synchrotron tomography to understand the mechanical behavior of materials under variety of conditions have been explored. We have described several in situ loading methodologies, challenges, and solutions. The provisions for alignment led to symmetrical crack front in the second generation in situ mechanical testing stage. The third generation in situ loading stage provided loadcontrol capability and additional stiffness to perform high R-ratio fatigue crack growth experiments. These loading stages were used for mechanical testing (monotonic and cyclic loading) in ambient air as well as in corrosive environments such as EXCO solution or moisture. 


\section{Competing interests}

The authors declare that they have no competing interests.

\section{Authors' contribution}

SS carried out experiments, analysis of data, and wrote the manuscript. JJW designed the testing jigs, carried out experiments, and analysis. PH helped with experimental analysis and image segmentation. XX and FDC provided experimental support at APS. NC helped design the experiments, ideas for crack growth and corrosion, and helped in writing the manuscript. All authors read and approved the final manuscript.

\section{Acknowledgements}

We acknowledge financial support from the Office of Naval Research, under contract number N000141010350

(Dr. Asuri Vasudevan, Program Manager). Use of the Advanced Photon Source was supported by the U.S. Department of Energy, Office of Science, Office of Basic Energy Sciences, under Contract No. DE-AC02-06CH11357. We also thank Carl Mayer at Arizona State University for useful discussions.

\section{Author details}

${ }^{1}$ Materials Science and Engineering, Arizona State University, Tempe, AZ 85287-6106, USA. ${ }^{2}$ Advanced Photon Source, Argonne National Laboratory, Argonne, IL, USA.

Received: 25 November 2013 Accepted: 21 February 2014

Published: 3 April 2014

\section{References}

1. Buffiere JY, Maire E, Adrien J, Masse JP, Boller E (2010) In situ experiments with x ray tomography: an attractive tool for experimental mechanics. Exp Mech 50:289-305

2. Maire E, Buffiere JY, Salvo L, Blandin JJ, Ludwig W, Letang JM (2001) On the application of X-ray microtomography in the field of materials science. Adv Eng Mater 3:539-546

3. Beckmann F, Grupp R, Haibel A, Huppmann M, Nothe M, Pyzalla A, Reimers W, Schreyer A, Zettler R (2007) In situ synchrotron x-ray microtomography studies of microstructure and damage evolution in engineering materials. Adv Eng Mater 9:939-950

4. Buffiere JY, Cloetens P, Ludwig W, Maire E, Salvo L (2008) In situ x-ray tomography studies of microstructural evolution combined with 3D modeling. MRS Bull 33:611-619

5. Williams JJ, Flom Z, Amell A, Chawla N, Xiao X, De Carlo F (2010) Damage evolution in SiC particle reinforced Al alloy matrix composites by X-ray synchrotron tomography. Acta Mater 58:6194-6205

6. Link T, Zabler S, Epishin A, Haibel A, Bansal M, Thibault X (2006) Synchrotron tomography of porosity in single-crystal nickel-base superalloys. Mater Sci Eng A 425:47-54

7. Caty O, Maire E, Bouchet R (2008) Fatigue of metal hollow spheres structures. Adv Eng Mater 10:179-184

8. Williams JJ, Chapman NC, Jakkali V, Tanna VA, Chawla N, Xiao X, De Carlo F (2011) Characterization of damage evolution in SiC particle reinforced Al alloy matrix composites by in-situ X-ray synchrotron tomography. Metall Mater Trans A 42:2999-3005

9. Maire E, Zhou S, Adrien J, Dimichiel M (2011) Damage quantification in aluminium alloys using in situ tensile tests in X-ray tomography. Eng Fract Mech 78:2679-2690

10. Withers PJ, Preuss M (2012) Fatigue and damage in structural materials studied by X-ray tomography. Annu Rev Mater Res 42:81-103

11. Guvenilir A, Breunig TM, Kinney JH, Stock SR (1997) Direct observation of crack opening as a function of applied load in the interior of a notched tensile sample of Al-Li 2090. Acta Mater 45(5):1977-1987

12. Williams JJ, Yazzie KE, Padilla E, Chawla N, Xiao X, De Carlo F (2013) Understanding fatigue crack growth in aluminum alloys by in situ X-ray synchrotron tomography. Int J Fatigue 57:79-85

13. Williams JJ, Yazzie KE, Phillips NC, Chawla N, Xiao X, Carlo FD, lyyer N, Kittur M (2011) On the correlation between fatigue striation spacing and crack growth rate: a three-dimensional (3-D) X-ray synchrotron tomography study. Metall Mater Trans A 42A:3845-3847

14. Khor KH, Buffiere JY, Ludwig W, Toda H, Ubhi HS, Gregson PJ, Sinclair I (2004) In situ high resolution synchrotron x-ray tomography of fatigue crack closure micromechanisms. J Phys Condens Matter 16:S3511-\$3515

15. Singh SS, Williams JJ, Xiao X (2012) Carlo FDe, Chawla N (2012) In situ three dimensional (3D) X-ray synchrotron tomography of corrosion fatigue in Al7075 alloy. In: Srivatsan TS, Imam AM, Srinivasan R (eds) Fatigue of Materials II: advances and emergences in understanding. Materials Science and Technology, Pittsburgh

16. Pyzalla A, Camin B, Lehrer B, Wichert M, Koch A, Zimnik K, Boller E, Reimers W (2006) In-situ observation of creep damage in $\mathrm{Al}_{-} \mathrm{Al}_{2} \mathrm{O}_{3}$ MMCs by synchrotron X-ray tomography. Int Centre Diffraction Data:1097-2102

17. Issac A, Sketa F, Reimers W, Caminb B, Sauthoff G, Pyzalla AR (2008) In situ 3D quantification of the evolution of creep cavity size, shape, and spatial orientation using synchrotron X-ray tomography. Mater Sci Eng A 478:108-118

18. De Carlo F, Tieman B (2004) High-throughput X-ray microtomography system at the advanced photon source beamline 2-BM. SPIE 5535:644-651, Ulrich Bonse, editors

19. Peele G, De Carlo F, McMahon PJ, Dhal BB, Nugent KA (2005) X-ray phase contrast tomography with a bending magnet source. Rev Sci Instrum 76:083707-1-5

20. De Carlo F, Albee P, Chu YS, Mancini DC, Tieman B, Wang SY (2002) High-throughput real-time X-ray microtomography at the advanced photon source. Proc SPIE 4503:1-13, U. Bonse, ed

21. Mikheevskiy S (2009) Elastic-plastic fatigue crack growth analysis under variable amplitude loading spectra. Dissertation, University of Waterloo, Ph.D 
22. Chawla N, Andres C, Jones JW, Allison JE (1998) Effect of SiC volume fraction and particle size on the fatigue resistance of a $2080 \mathrm{Al} / \mathrm{SiCp}$ composite. Metall Mater Trans A 29:2843-2854

23. Plastic chemical resistance chart, plastic international., http//wwww.plasticsintl.com/plastics_chemical_resistence_chart.html

24. Holroyd NJH, Scamansc GM (2011) Crack propagation during sustained-load cracking of Al-Zn-Mg-Cu aluminum alloys exposed to moist air or distilled water. Metall Mater Trans A 42:3979-3998

doi:10.1186/2193-9772-3-9

Cite this article as: Singh et al:: In situ experimental techniques to study the mechanical behavior of materials using X-ray synchrotron tomography. Integrating Materials and Manufacturing Innovation 2014 3:9.

Submit your manuscript to a SpringerOpen ${ }^{\circ}$ journal and benefit from:

- Convenient online submission

- Rigorous peer review

- Immediate publication on acceptance

- Open access: articles freely available online

- High visibility within the field

- Retaining the copyright to your article

Submit your next manuscript at $\boldsymbol{s p r i n g e r o p e n . c o m ~}$ 